Scientific Journal of Hamadan Nursing \& Midwifery Faculty - ISSN 2008-2819

\title{
The Effect of Health Belief Model Education on Nutrition Behavior of Boys in Secondary Schools in Hamadan
}

\author{
Nahid Mohammadi', Meysam Hooshian², Afsar Omidi*3, Alireza Soltanian ${ }^{4}$ \\ 1. Instructor, Chronic Diseases (Home Care) Research Center, Hamadan University of Medical Sciences, Hamadan, Iran \\ 2. MSc., Department of Nursing, School of Nursing and Midwifery, Hamadan University of Medical Sciences, Hamadan, \\ Iran \\ 3. Instructor, Chronic Diseases (Home Care) Research Center, Hamadan University of Medical Sciences, Hamadan, Iran \\ 4. Professor, Modeling of Noncommunicable Disease Research Center, Hamadan University of Medical Sciences, \\ Hamadan, Iran
}

\begin{tabular}{|c|c|}
\hline Article Info & ABSTRACT \\
\hline $\begin{array}{l}\text { Received: 2017/09/03; } \\
\text { Accepted: 2017/09/17; } \\
\text { Published Online: 2018/08/04 }\end{array}$ & $\begin{array}{l}\text { Introduction: The Adolescents need healthy nutrition education more than any } \\
\text { other groups. In present study, the effect of Health Belief Model education on } \\
\text { nutrition behavior of secondary boy students was investigated. }\end{array}$ \\
\hline & $\begin{array}{l}\text { Methods: This pre and post test semi-experimental study with two groups was } \\
\text { carried out on } 120 \text { boys of secondary schools in Hamadan. A randomized cluster }\end{array}$ \\
\hline 10.30699/sjhnmf.26.6.397 & $\begin{array}{l}\text { sampling method and relative randomize method were used in the first and second } \\
\text { stages respectively. At first both groups completed a questionnaire which was based }\end{array}$ \\
\hline $\begin{array}{l}\text { Use your device to scan } \\
\text { and read the article online }\end{array}$ & $\begin{array}{l}\text { on Health Belief Model and then instructions were given to intervention group in } \\
\text { three sessions ( } 45 \text { minutes) on the basis of HBM model. Two months later, data were } \\
\text { collected via questionnaires in two groups again. Statistical analysis of the data was } \\
\text { performed by SPSS23, the statistical tests were Repeated Measurement ANOVA } \\
\text { analysis. }\end{array}$ \\
\hline
\end{tabular}

Results: The two groups were similar in demographic characteristics and structure of the HBMModel at the beginning of the study. After the intervention, the mean scores of Health Belief Model structures excepted for the perceived barriers and the average nutritional behavior in the experimental group were more than that of the control group's. In the area of perceived barriers, the mean scores increased in the control group. Repeated Measurement ANOVA showed significant differences between all the domains of the model except for the perceived severity $(P<0.05)$.

Conclusion: According to the results of this study (Health Belief MODEL on Nutrition Behavior) the mean scores increased on the basis of model structures (except for the barriers) after training. So we suggest that health education programs be applied instead of applying traditional instructions.

Keywords: Nutrition behavior, Health Belief Model, Boys secondary schools

Corresponding Information:

Afsar Omidi, Associate Professor, Instructor, Chronic Diseases (Home Care) Research Center,

Hamadan University of Medical Sciences, Hamadan, Iran. Email: afsar_omidi@yahoo.com

Copyright () 2019, Sci J Hamadan Nurs Midwifery Fac. This is an open-access article distributed under the terms of the Creative Commons Attribution-noncommercial 4.0 International License which permits copy and redistribute the material just in noncommercial usages, provided the original work is properly cited.

\section{How to Cite This Article:}

Mohammadi N, Hooshian M, Omidi A, Soltanian A. The Effect of Health Belief Model Education on Nutrition Behavior of Boys in Secondary Schools in Hamadan. Sci J Hamadan Nurs Midwifery Fac. 2019; 26 (6):397-406 


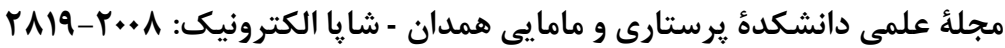

مقالهُ يروهشى

تأثير آموزش براساس مدل اعتقاد بهداشتى بر رفتارهاى تغذيهاى دانش آموزان بسر

دورة اول متوسطة شهر همدان

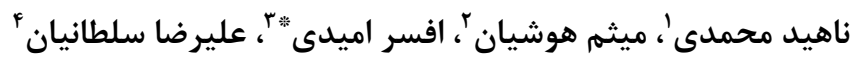

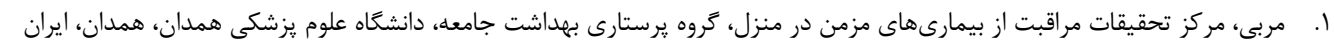

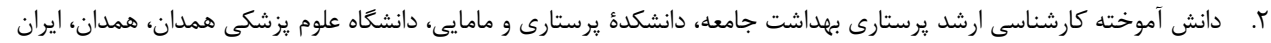

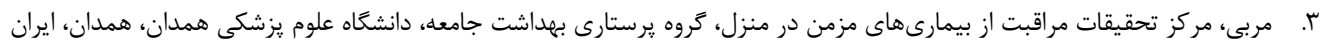

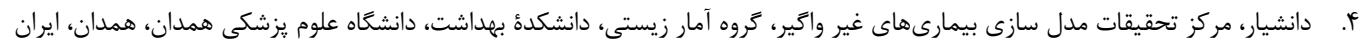

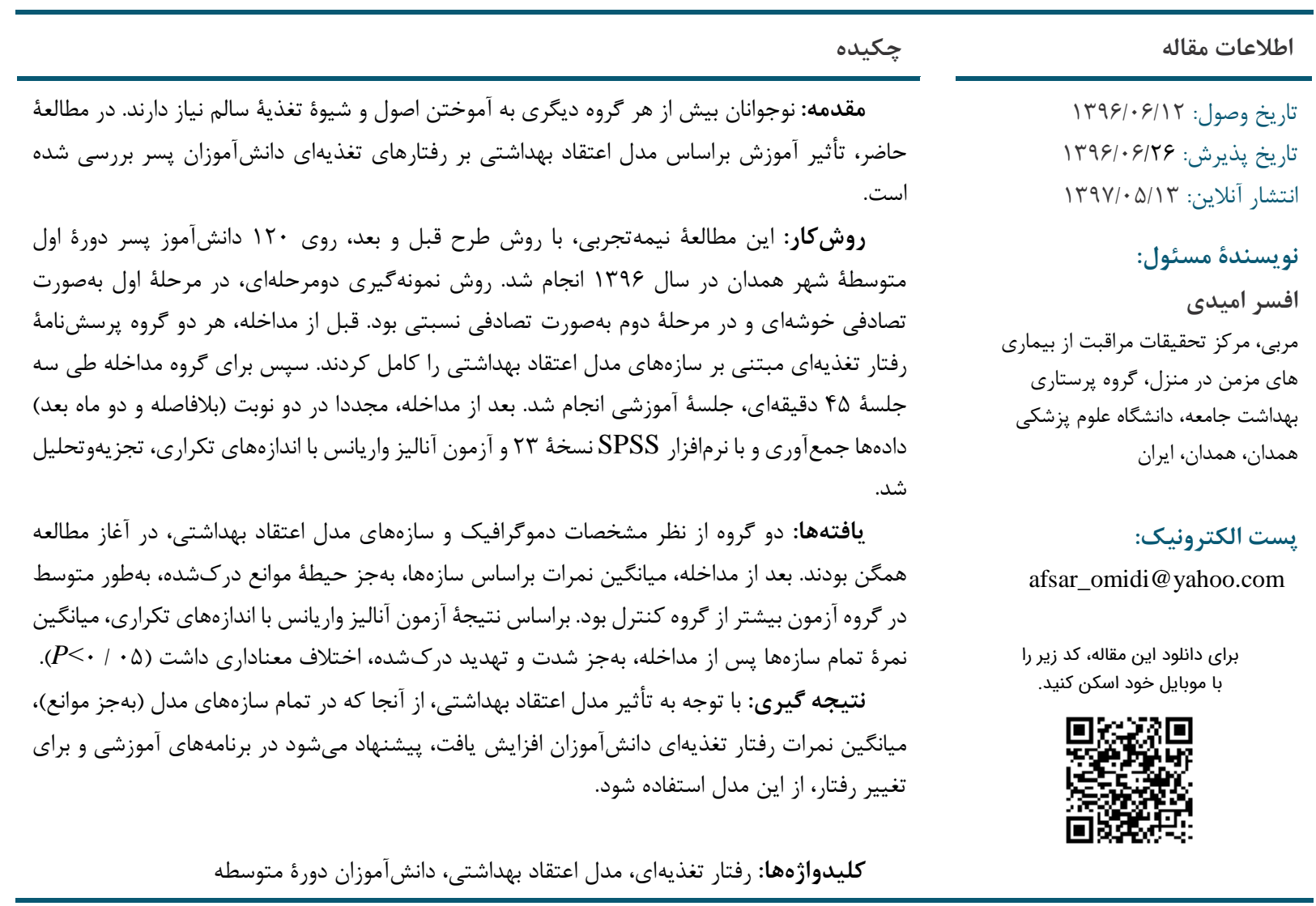

مقدمه

دور از رفتارهاى يرخطر است كه در اين بين، تغذئه مناسب

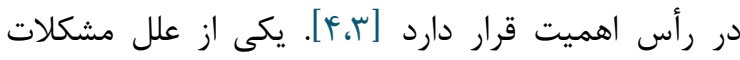
تغذيهاى نوجوانان نداشتن آكَاهى از اهميت مصرف موان مواد غذايى متنوع و زيروى نكردن از رزيمهاى غذايى نادرست مانند مصرف انواع غذاهاى آماده، شيرينى، شكلات و ... است. مصرف اين نوع مواد غذايى نهتنها باعث كاهش كارايى

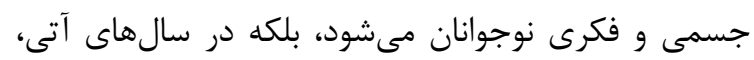
اثرات سوء خود را به شكل هاى گوناگون مانند ابتلا به بيمارى
نوجوانى مرحلة مهمى از رشد و تكامل و دوره بحرانى

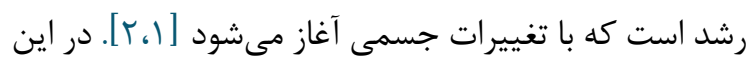
دوره، رشد سريع جسمى و تكامل رفتارى ـ شناختى، تغذية

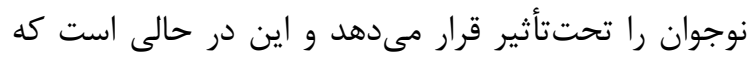
نياز به انرزى و مواد مغذى مانند يروتئين، كلسيم و آهن نيز

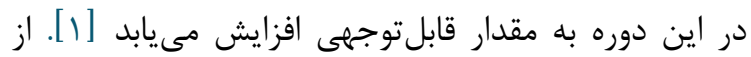

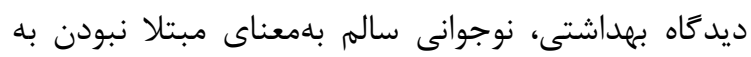

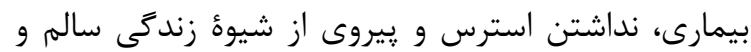


ضرورت دارد تا بتوانند از شيوه زندگى سالم پيروى

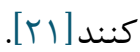

از آنجا كه يكى از زمينههاى كارى برستاران تلاش براى

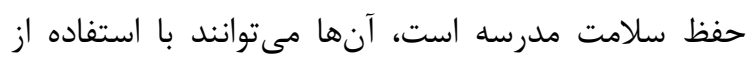

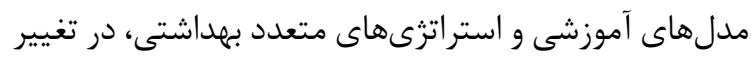

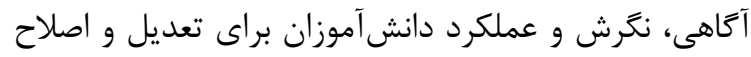

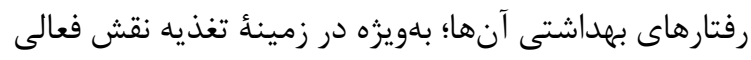

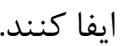

همجنين به دليل هزينهاى بالاى مراقبتهاى

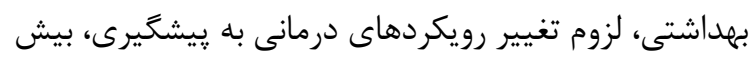

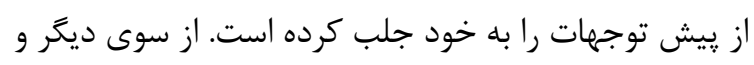
با توجه به تأكيدهاى سازمان جهانى بهراشت بهات بر اهميت

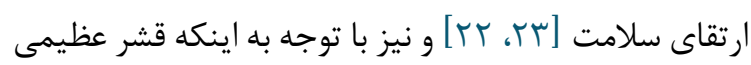
از جامعه را نوجوانان تشكيل مىدهند، مطالعات انجامشده

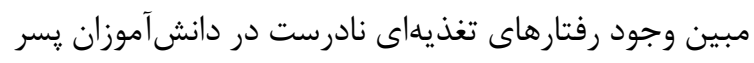

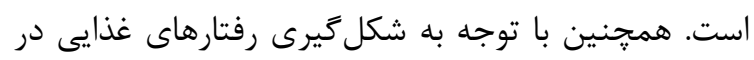

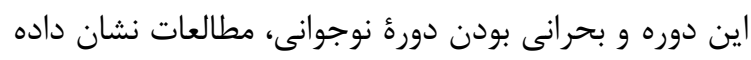

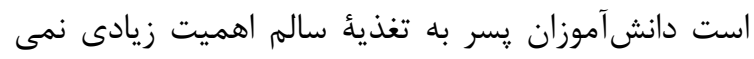

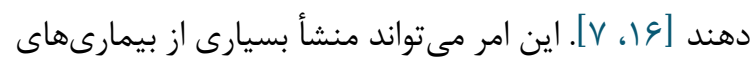

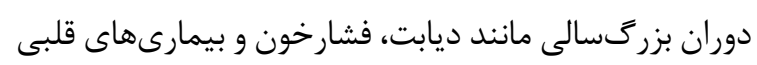

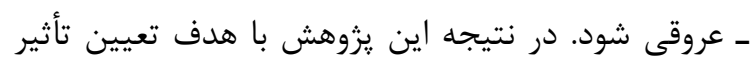

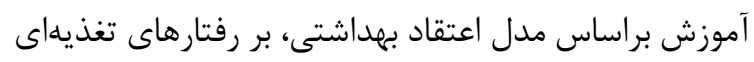

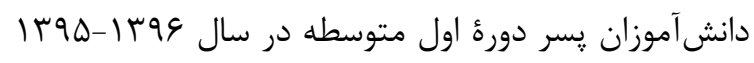
در شهر همدان، انجام شده است.

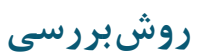

اين مطالعه نيمهتجربى دو گروهى، با طرح قبل و بعد

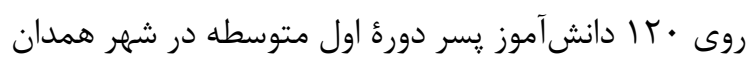

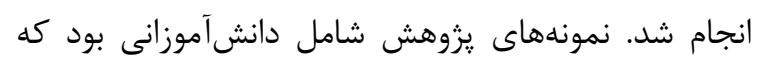

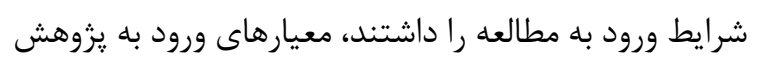

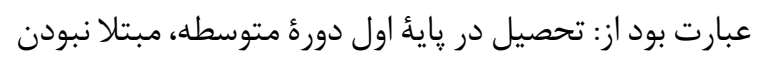

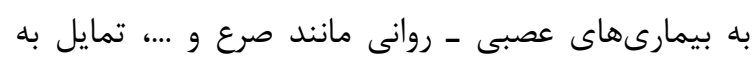

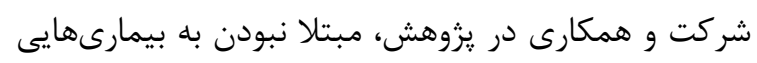

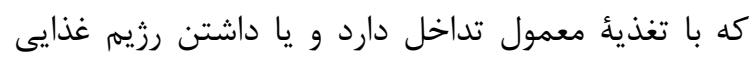
خاص. معيارهاى خروج از مطالعه نيز تمايل نداشتن به ادامئ دأن

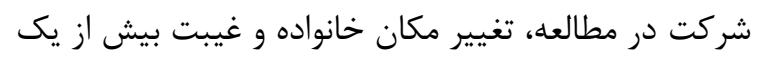

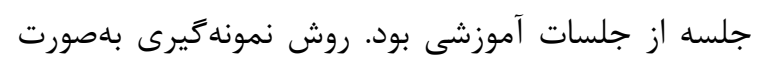

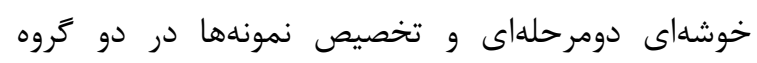

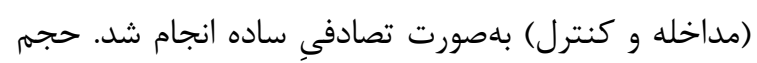

هاى ديابت، افزايش فشارخون، بيمارىهاى قلبى و عروقى،

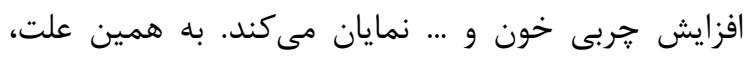
رعايت تغذية صحيح و داشتن برنامهٔ غذايى منادي مناسب كه شامل

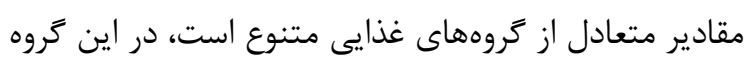
ضرورت دارد [ب].

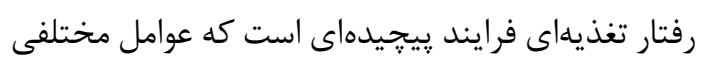

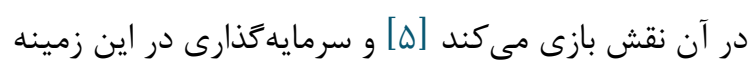

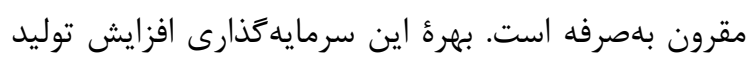

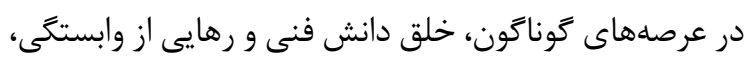

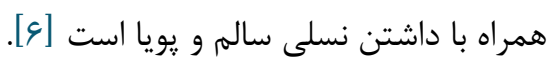
تغذيه در دانشآموزان به دلايلى مانند تأمين مواد سازنده

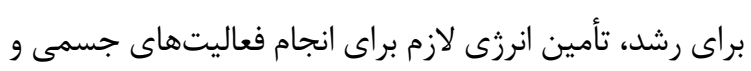

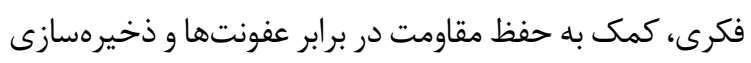

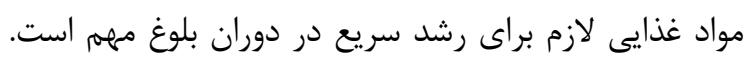

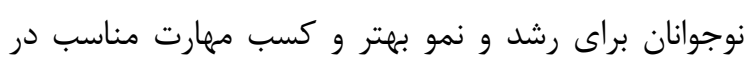

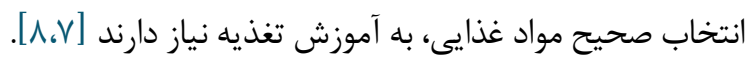

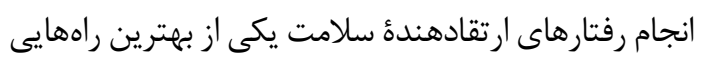

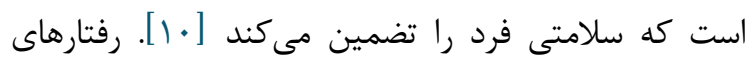
ارتقادهنده سلامت شامل انجام كارهايى است كل فه به توانمند

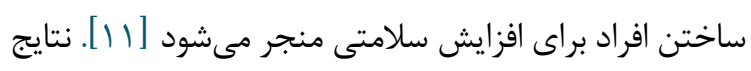

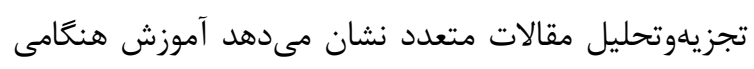

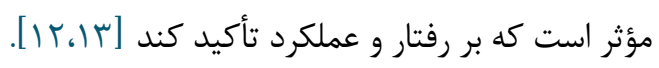

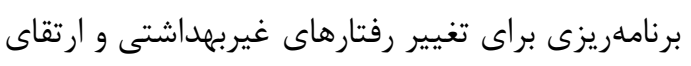
سلامت، مدلهاى مختلفى دارد كه يكى از آنهاي آنها مدل اعتقاد

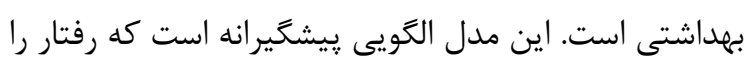

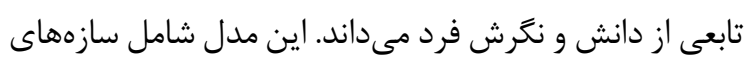

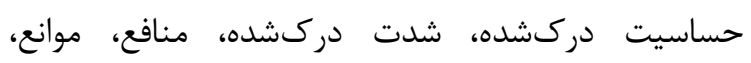

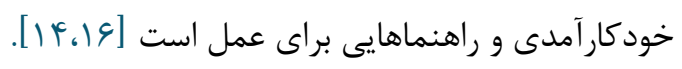

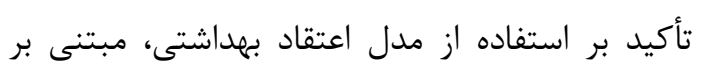

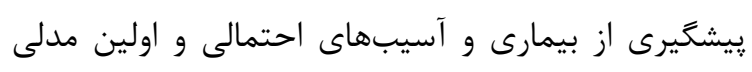

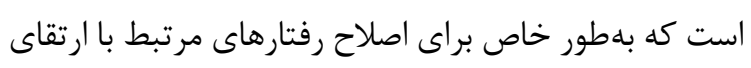

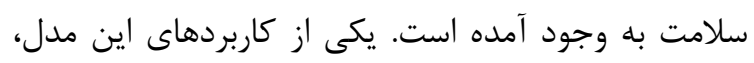

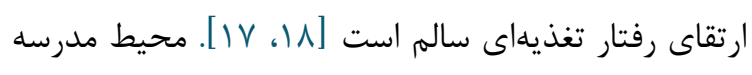

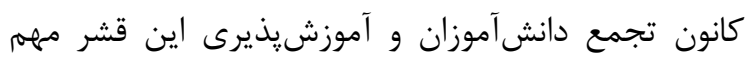

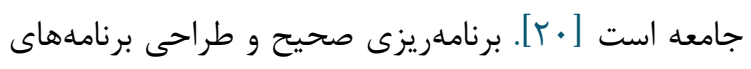

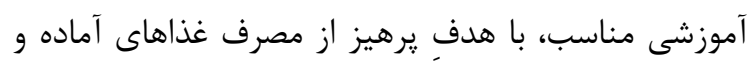

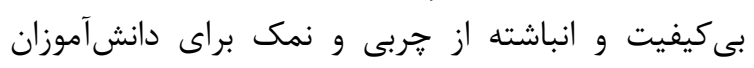


اعتقاد بهداشتى مربوط به رفتار تغذيهاى، بهصورت ييشآزمون از سوى هر دو كروه (كنترل و مداخله) كامل

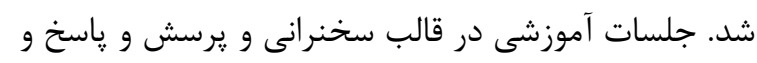

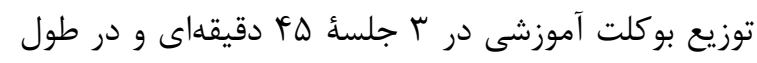

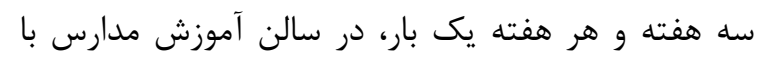

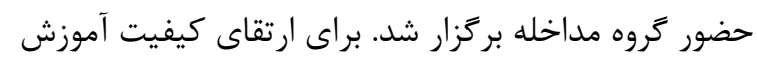

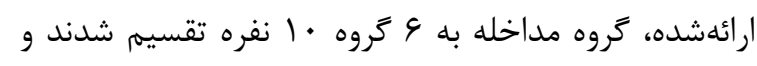

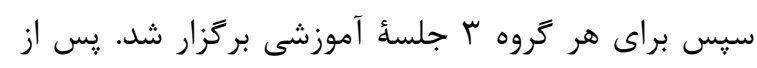

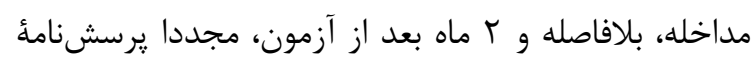

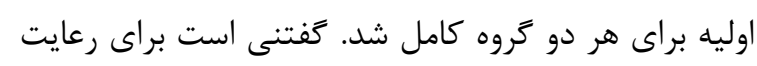

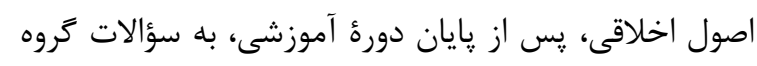

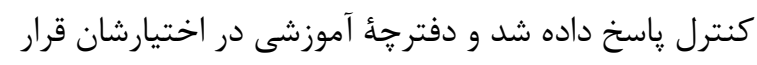

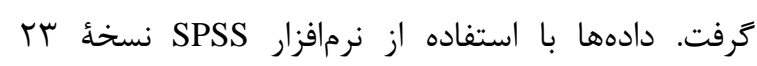

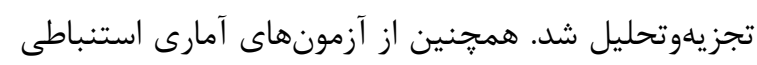

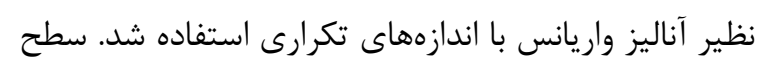
معنادارى تمام آزمونهاى آمارى كمتر از هـ • • • بوده است.

\section{يافته ها}

از نظر مشخصات دموكرافيك، بيشتر افراد مطالعه شده

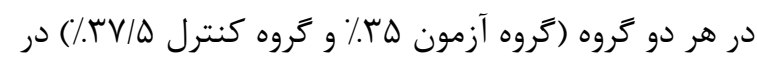

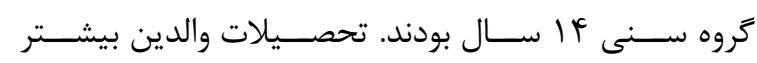

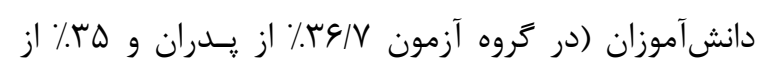

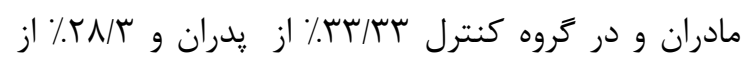

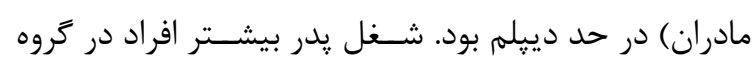

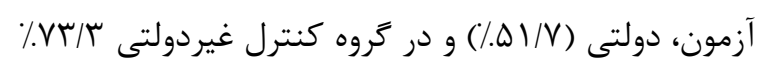

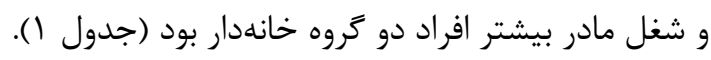

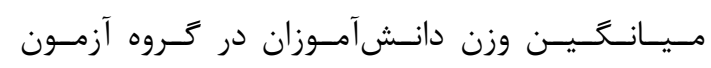
( ) ( ) (

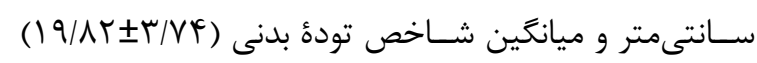

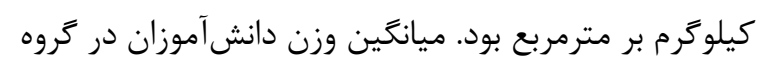

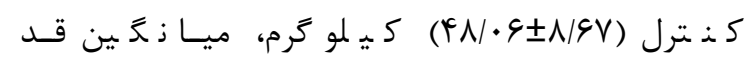

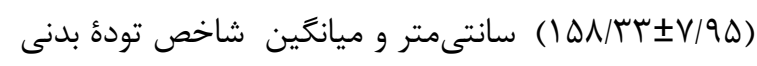

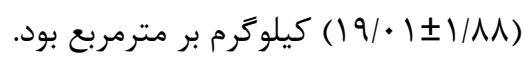

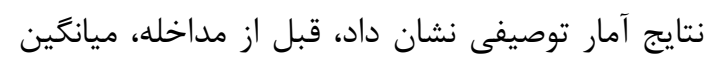

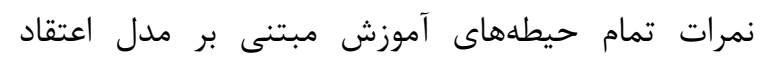

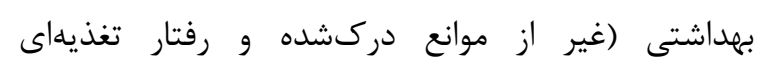

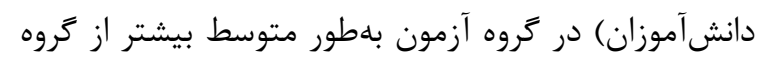

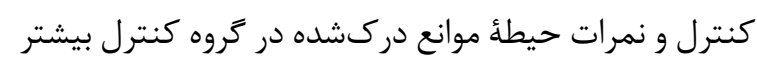

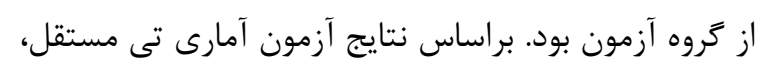

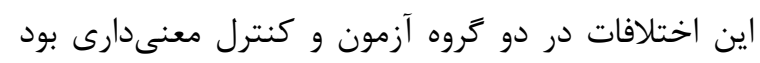

Rمونه در هر يك از تروههاى مطالعه با استفاده از نرمافزار

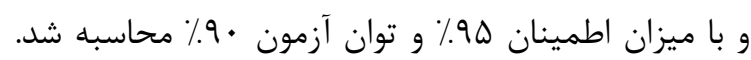
همجنين اختلاف قابلانتظار (Ali

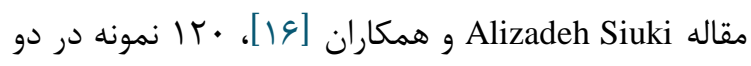

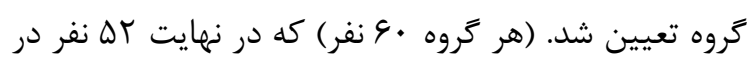

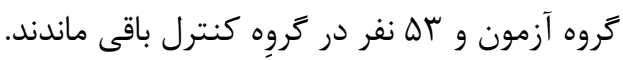

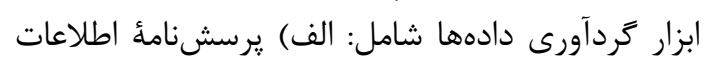

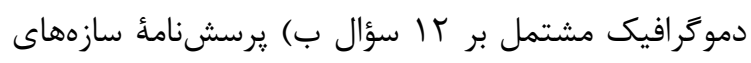

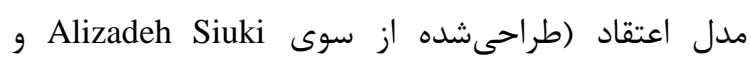

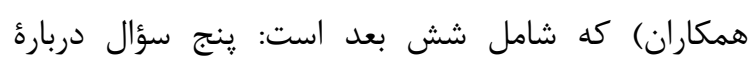

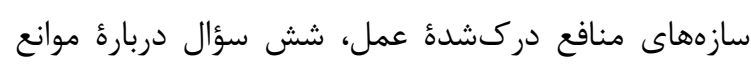

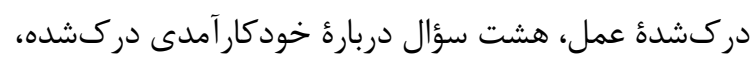

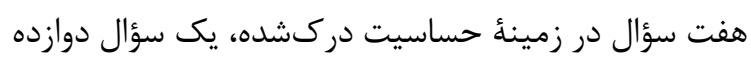

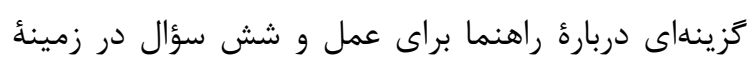
شدت دركشده (در مجموع سب سؤال) كه در مقياس ليكرت

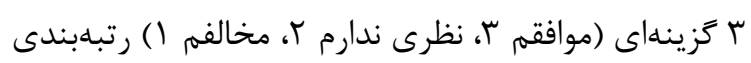

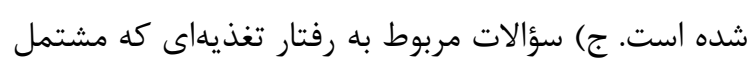

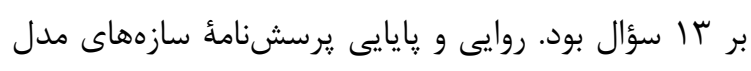

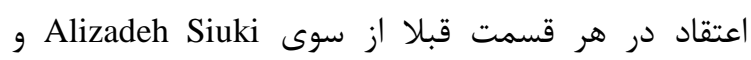

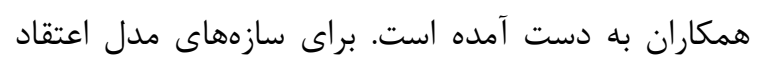

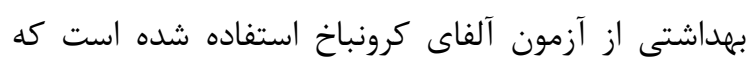

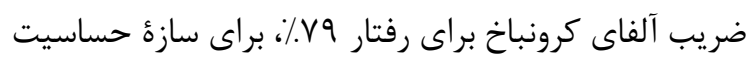

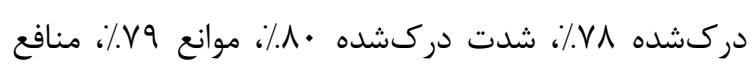

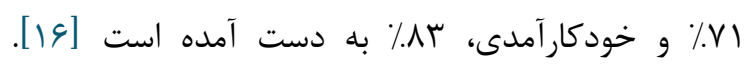

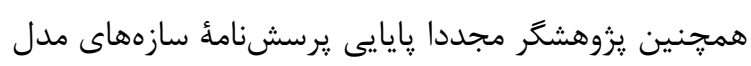

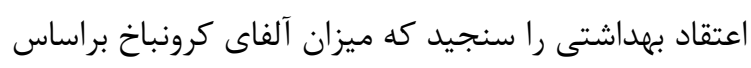

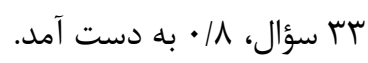
براى تعيين اعتبار (روايى) صورى و محتوايى يرسش إشنامه،

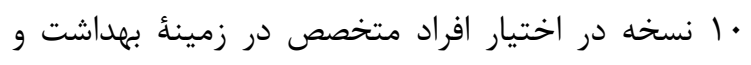

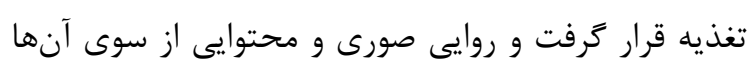

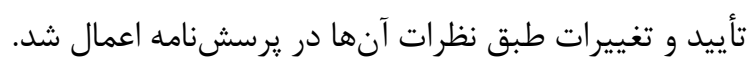

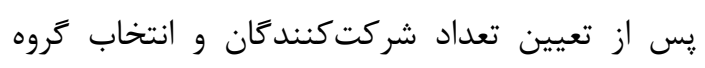

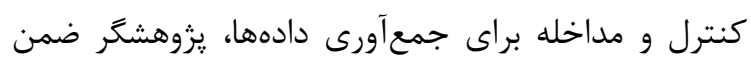

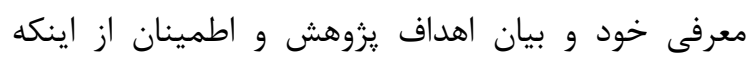

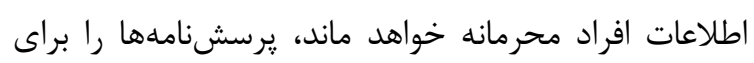

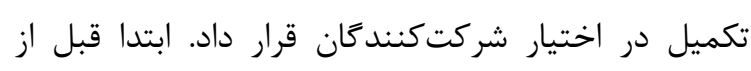

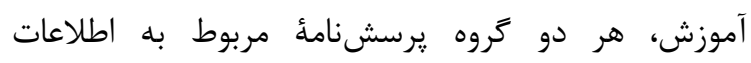

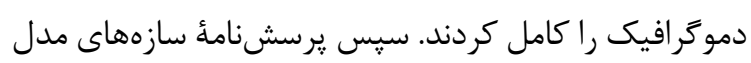


دركشده، منافع دركشده، تهديد دركشده و و

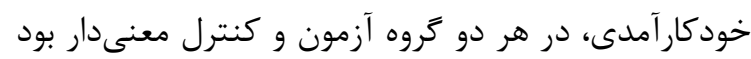

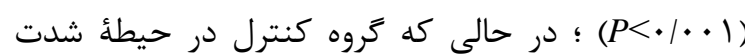

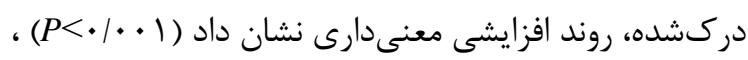

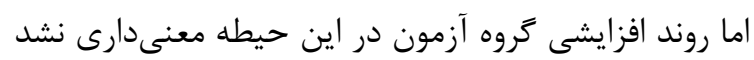

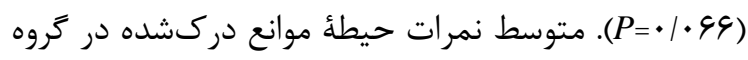

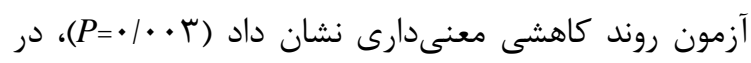

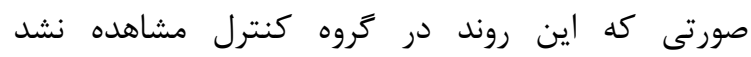

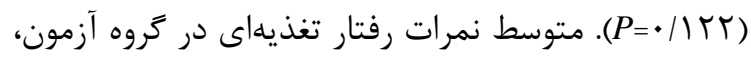

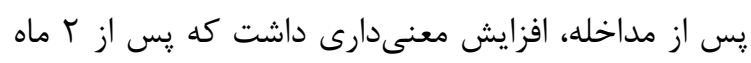

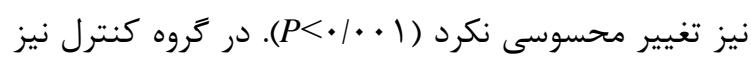

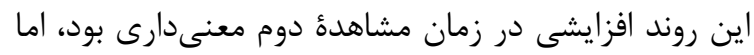

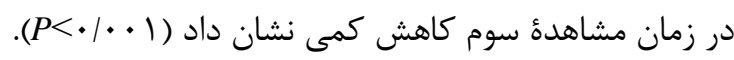

(

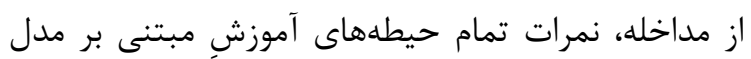

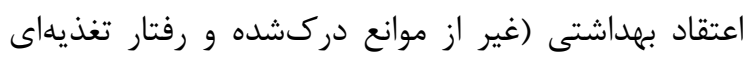

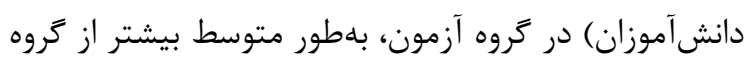

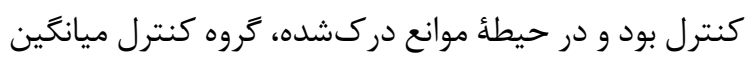
نمرات بيشترى نسبت به كروه آزمون داشت. براساس نتايج

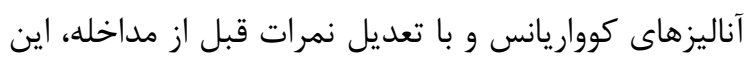
اختلافات در تمام حيطههاى مدل اعتقاد بهداشتى (غير از

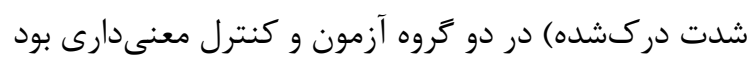
$(P<\cdot / \phi)$

طبق جدول شماره ז، نتايج نشان مى دهد متوسط نمرات آكاهى و تمام حيطههاى مدل اعتقاد بهداشتى (غير از موانع

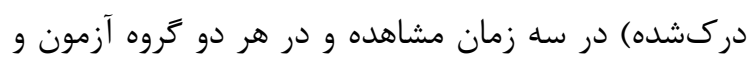

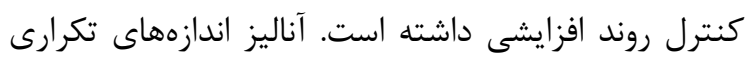

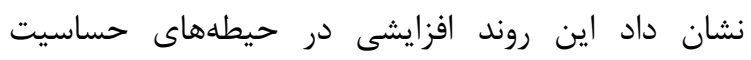

جدول شماره ا. توزيع متغيرهاى دموكرافيك در دانش آموزان به تفكيك كروه آزمون و كنترل

\begin{tabular}{|c|c|c|c|c|}
\hline آزمارى & 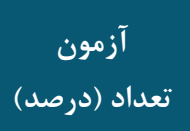 & 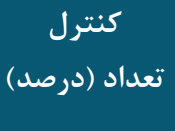 & تروه & متغير \\
\hline \multirow{4}{*}{ 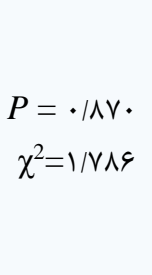 } & $(1 \Delta)^{9}$ & $(1 \cdot / V) 9$ & r & \multirow{4}{*}{ سن } \\
\hline & $(r \Delta) r^{\prime}$ & $(r V / Q) Y I$ & If & \\
\hline & ו & (4 & 10 & \\
\hline & $(10) 9$ & $(\mid V / 9) \mid$. & 19 & \\
\hline \multirow{3}{*}{$\begin{array}{l}P=\cdot / 099 \\
\chi^{2}=r / V r \wedge\end{array}$} & $(K \Psi / F) \backslash F$ & $(r \mid / V) \| r$ & زير دييلم & \multirow{3}{*}{ تحصيلات } \\
\hline & $(Y G / V) Y T$ & • & دييلم & \\
\hline & $($ (T/q)YF & $(F \Delta) r V$ & بالاتر از دييلم & \\
\hline \multirow{3}{*}{$\begin{array}{l}P=\cdot|\cdot \Delta| \\
\chi^{2}=\mid 1 / V r \wedge\end{array}$} & 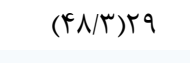 & $(F \cdot) T^{F}$ & زير دييلم & \multirow{3}{*}{ تحصيلات } \\
\hline & ו & $(Y \Lambda / T)) \vee$ & دييلهم & \\
\hline & $(\mid \varepsilon / V) \mid$ & $(r) / V) 19$ & بالاتر از دييلم & \\
\hline \multirow[t]{2}{*}{$\begin{array}{l}P=\cdot / 4 q 4 \\
\chi^{2}=1 / 4 \cdot \uparrow\end{array}$} & $(T \Delta) \backslash \Delta$ & $(r \Delta) r^{\prime}$ & شاغل & \multirow{2}{*}{ شغل مادر } \\
\hline & $(V \Delta) F \Delta$ & $(q \Delta))^{\prime}$ & خانهدار & \\
\hline \multirow{2}{*}{$\begin{array}{l}P=\cdot / \cdot r r \\
\chi^{2}=\Lambda / V q 1\end{array}$} & $(\Delta I / V) \Gamma \mid$ & $(Y \varphi / V) \backslash \varepsilon$ & دولتى & \multirow{2}{*}{ شغل پيدر } \\
\hline & 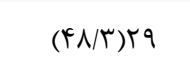 & $(V T / T) F F$ & غيردولتى & \\
\hline
\end{tabular}


Y. F تأثير آموزش براساس مدل اعتقاد بهداشتى بر رفتارهاى تغذيهاى ....

جدول شماره r. مقايسئ ميانعَين نمرات آكاهى و حيطههاى مدل اعتقاد بهداشتى و رفتار تغذيهاى دانش آموزان، در كروه آزمون و كنترل در ب زمان مشاهده

\begin{tabular}{|c|c|c|c|c|c|}
\hline آزمون انداز ههاى & \multicolumn{3}{|c|}{ انحرافمعيار \ميانَين } & \multirow{2}{*}{ 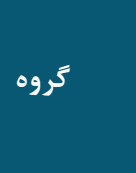 } & \multirow[b]{2}{*}{ متغير ها } \\
\hline تكرارى & دو مداهل بعد از & مداخله بلها بعد از & قبل از مداخله & & \\
\hline $\begin{array}{l}P<\cdot / . \cdot 1 \\
\mathrm{~F}=r \cdot 19 \Delta\end{array}$ & $F Q / \cdot F \pm r / G T$ & $F \Delta / T F \pm r / 9 \mid$ & $\varphi \mid / r \cdot \pm \varepsilon / \Delta r$ & كنترل & \\
\hline 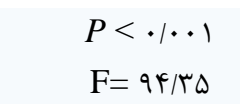 & $F \wedge / \& V \pm \cdot / V q$ & $\vee \wedge / \wedge q \pm \cdot / \& q$ & $F \Delta / T Y \pm T / T Y$ & آزمون & اكاهى \\
\hline $\begin{array}{l}P<\cdot|\cdot \cdot| \\
\mathrm{F}=\mid \Delta / r .\end{array}$ & $|V / 9 \Lambda \pm r / r|$ & $\mid V / \wedge \Delta \pm r / r q$ & $\mid V / \backslash \Lambda \pm r / F r$ & كنترل & \\
\hline $\begin{array}{l}P<\cdot / . .1 \\
\mathrm{~F}=q \cdot / r q\end{array}$ & $r \cdot / \& V \pm \cdot / V q$ & $r \cdot / 4 \varepsilon \pm 1 / 1 \varepsilon$ & $19 / r T \pm T / 49$ & آزمون & حساسيت دركشده \\
\hline $\begin{array}{l}P<\cdot|\cdot \cdot| \\
\mathrm{F}=\mid r / \Delta r\end{array}$ & $\mid Q / \Delta T \pm T / T F$ & $\mid Q / r \varepsilon \pm T / \cdot r$ & $\mid F / T F \pm T / T r$ & كنترل & \\
\hline $\begin{array}{l}P=.1 .99 \\
F=r / r F\end{array}$ & $\mid \& / R V \pm \cdot / \Lambda V$ & $|q /| \uparrow \pm \cdot|\Lambda|$ & $10 / q 4 \pm 1 / \wedge q$ & آزمون & شدت دركشده \\
\hline $\begin{array}{c}P<\cdot / \cdot \cdot 1 \\
\mathrm{~F}=q / 9 r\end{array}$ & $|r / V 4 \pm| / r q$ & $|r / \Delta T \pm| / r \Delta$ & $\mid r / V G \pm 1 / 9 V$ & كنترل & \\
\hline $\begin{array}{l}P<\cdot / \cdot \cdot 1 \\
\mathrm{~F}=r \Delta / \cdot \Delta\end{array}$ & $\mid F / 9 T \pm \cdot / T V$ & $\mid \psi / \Lambda \cdot \pm \cdot / \Delta \Delta$ & $1 r / \Delta \cdot \pm 1 / q r$ & آزمون & منافع دركشده \\
\hline $\begin{array}{l}P=\cdot / / r r \\
F=r / r q\end{array}$ & 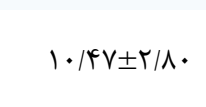 & $1 \cdot / r \cdot \pm r / \Lambda \Delta$ & $1 \cdot \mid \Lambda \varepsilon \pm r / N \varepsilon$ & كنترل & \\
\hline $\begin{array}{l}P=\cdot / \cdot r r \\
\mathrm{~F}=\mathrm{V} / q \mathrm{~V}\end{array}$ & $N / \cdot V \pm \cdot / 9 \mu$ & $N / T V \pm \cdot / 9 \varphi$ & $q / \cdot \pm \pm 1 / \wedge r$ & آزمون & موانع دركشده \\
\hline $\begin{array}{l}P<\cdot|\cdot \cdot| \\
\mathrm{F}=|\mathrm{V} /| \Lambda\end{array}$ & $r / \Delta \mid \pm r / 1 T$ & $r / r \mid \pm r / 9 q$ & $r \cdot / 1 \wedge \pm r / q q$ & كنترل & \\
\hline $\begin{array}{l}P<\cdot / \cdot \cdot 1 \\
\mathrm{~F}=\Delta F / T q\end{array}$ & $r G / 9 F \pm 1 / r T$ & $r q|9| \pm 1 / 4 q$ & 促 & آزمون & تهديد دركشده \\
\hline $\begin{array}{l}P<\cdot / \cdot 1 \\
\mathrm{~F}=r \mid / r r\end{array}$ & $19 / 4 T \pm T / 10$ & $|9 / r| \pm r / r \Lambda$ & $\mid V / \backslash \Lambda \pm T / A r$ & كنترل & \\
\hline $\begin{array}{l}P<. / .1 \\
\mathrm{~F}=119 / 94\end{array}$ & $r r / T \Psi \pm / / r$ & $r r / 9 \Lambda \pm 1 / \cdot V$ & $19 / r T \pm T / 49$ & آزمون & خود كارأمدى \\
\hline $\begin{array}{l}P<\cdot \mid \cdot \cdot 1 \\
\mathrm{~F}=r \mid / r q\end{array}$ & $\mid V / \cdot \wedge \pm r / q \mu$ & $I V / r F \pm r / V V$ & $|\Delta| \cdot V \pm \Psi / T$. & كنترل & \\
\hline $\begin{array}{c}P<\cdot \mid \cdot \cdot 1 \\
\mathrm{~F}=r|1 / r q|\end{array}$ & $r \digamma / \Lambda \Lambda \pm r / \Delta$. & $r F / \Lambda \Lambda \pm r / q r$ & $\mid V / A V \pm r / r q$ & آزمون & رفتار تغديهاى \\
\hline
\end{tabular}

مىدهد گروه آزمون و كنترل، قبل از مداخله، از نظر مشخصات جمعيتشناسى همكن بودند.

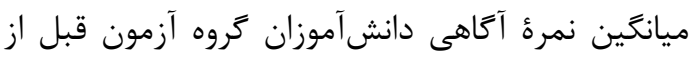

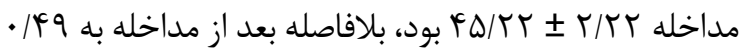

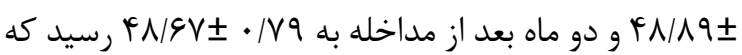

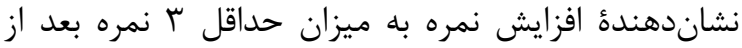
يزوهش حاضر با هدف تعيين تأثير آموزش براساس مدل

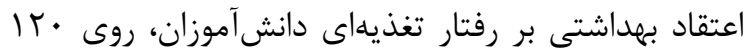

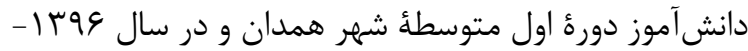
ه9 با انجام شد. يافتههاى بلددست آمده از اين مطالعه نشان 
راهنما براى عمل، در درجة اول مادر و در درجهٔ دوم بدر بود

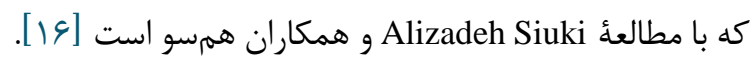
در بعد مقايسٔ منافع دركشده، معلوم شد اختلاف

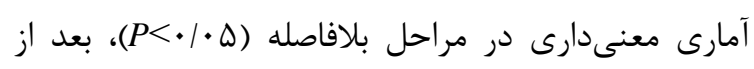

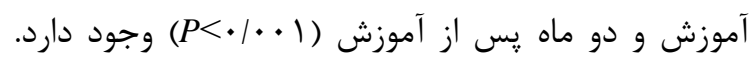

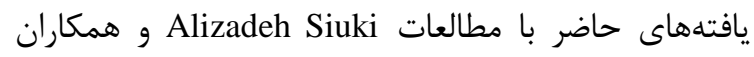

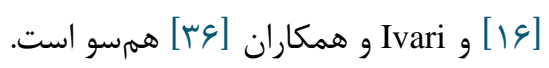

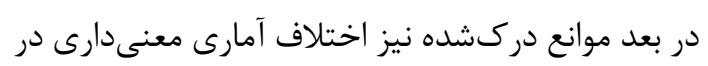

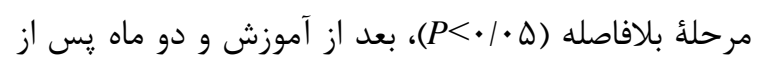

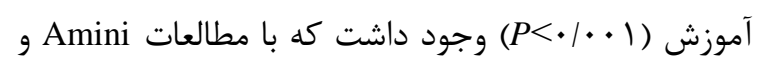

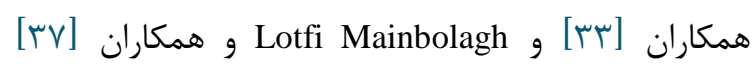

همسو بوده است.

در زمينأ تهديد دركشده، نتايج نشان داد اختلاف

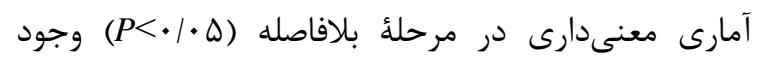

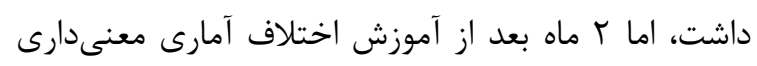
(P</FrV) Alizadeh Siuki

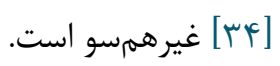

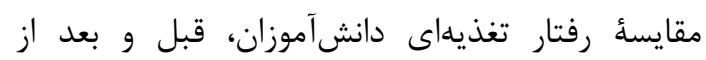

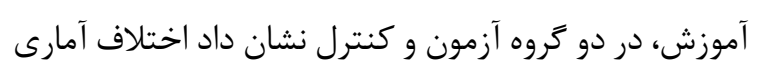

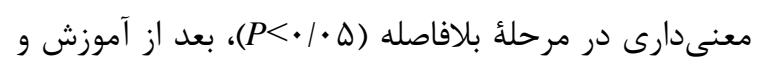

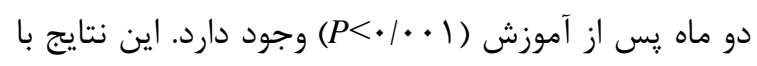

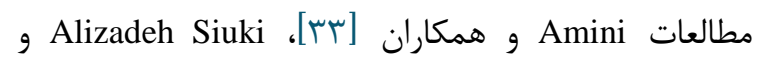

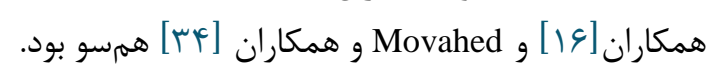

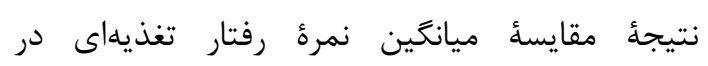

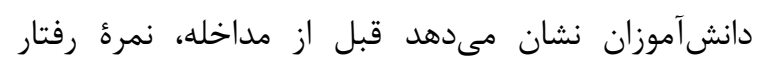

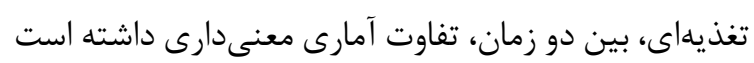

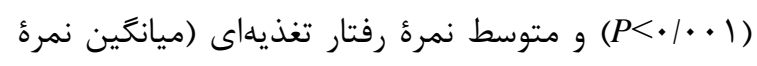

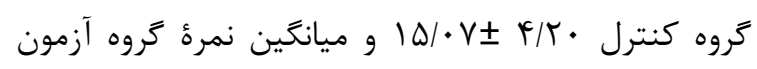

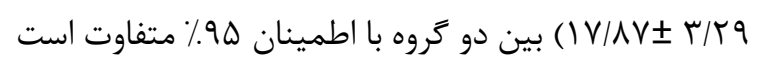

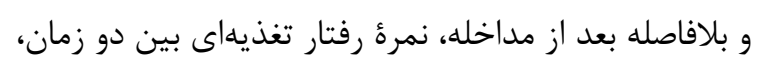

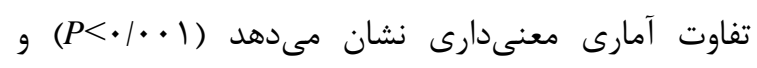

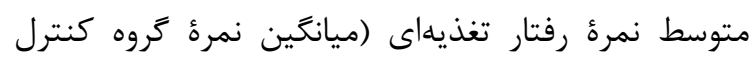

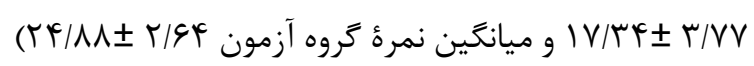

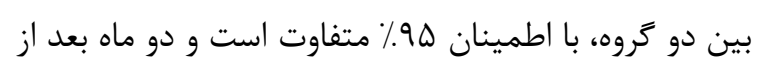

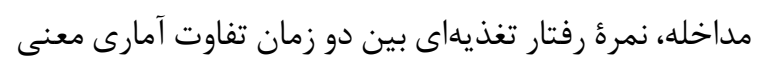

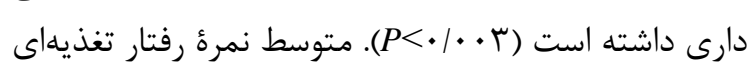

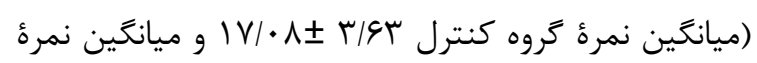

آموزش است. ميانكين نمره آكاهى بين دو كروه آزمون و

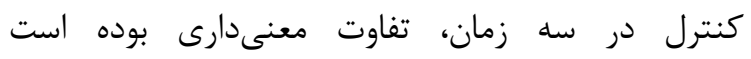

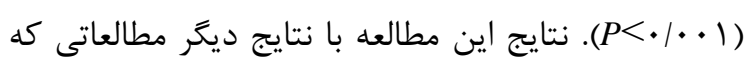

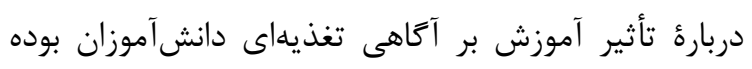

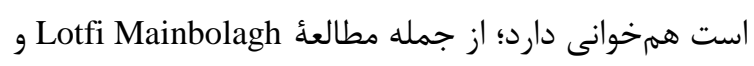

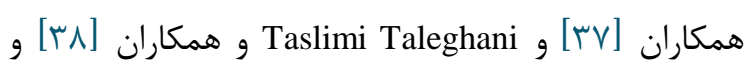

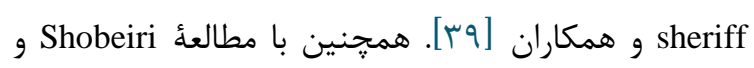

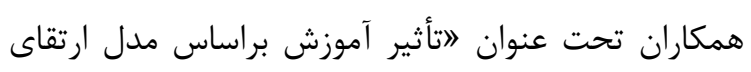

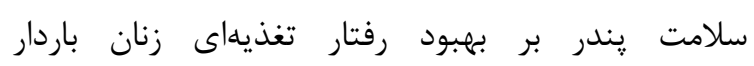

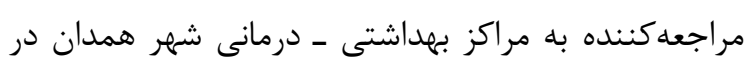

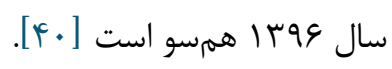

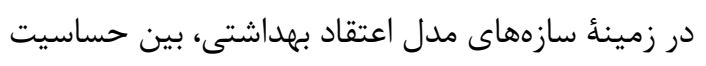

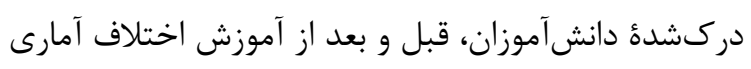

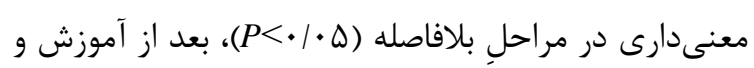

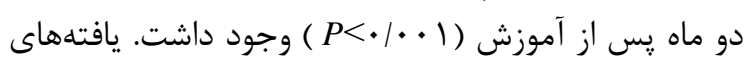
حاضر با مطالعه Amini و و همكاران، تحت عنوان التأثير

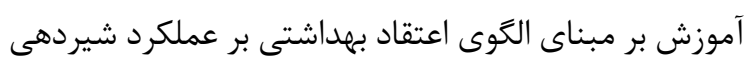

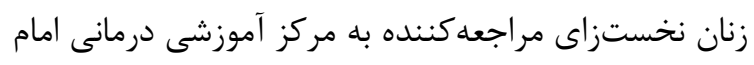

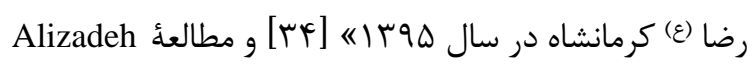

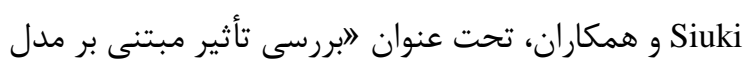

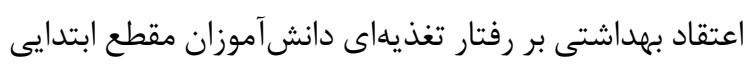

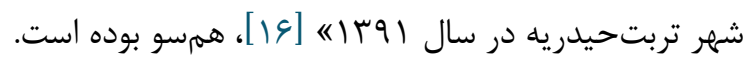

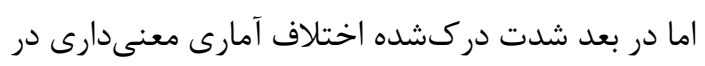

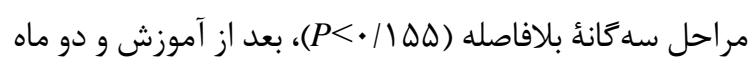

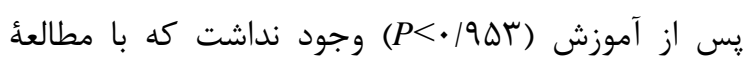
و و همكاران [ب Movahed

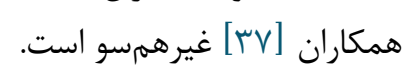

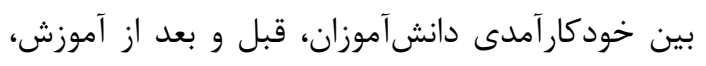

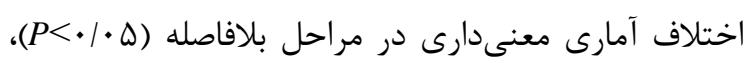

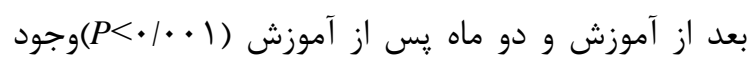

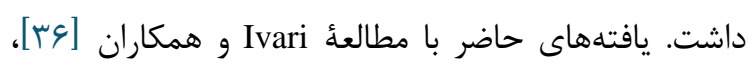
و همكاران [r Movahed

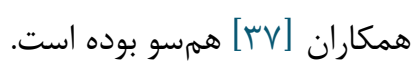
در بعد راهنما براى عمل، نتايج حاكى از اختلاف آهاف آمارى

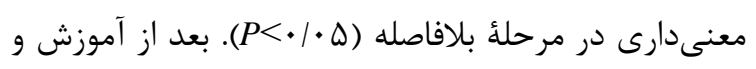

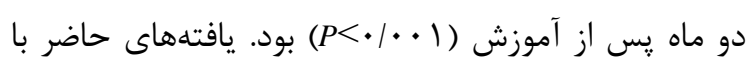

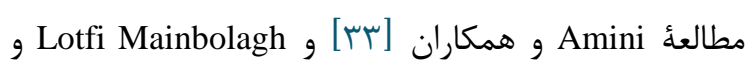

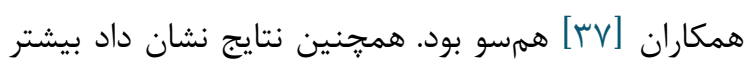




$$
\begin{aligned}
& \text { آموزشى كه درباره تغيير رفتار و پيشخيرى صورت مى گيرد } \\
& \text { از اين مدل استفاده شود. } \\
& \text { سياسَزارى }
\end{aligned}
$$

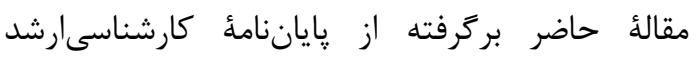

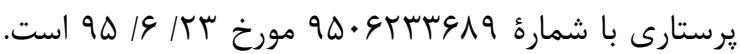$$
\text { كفتنى است اين طرح در كميتأ اخلاق حوزه معاونت }
$$$$
\text { تحقيقات و فناورى دانشگاه علوم يزشكى همدان با كد }
$$$$
\text { IRCT و IR.UMSHA.REC.13930304 }
$$$$
\text { 2016101925846N3 ثبت شده است. يزوهشگران بر خود }
$$$$
\text { لازم مى }
$$$$
\text { همدان، به دليل تصويب و حمايت از اين پاياننامه قدردانى }
$$

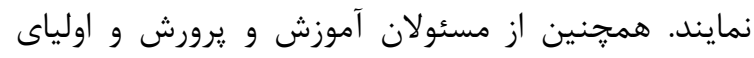

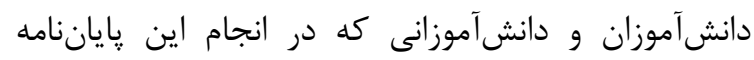$$
\text { همكارى داشتهاند، سياسگزارى موزى كنيند. }
$$$$
\text { تعارض در منافع }
$$

بين نويسندگًان هيجَّونه تعارضى در منافع وجود ندارد
كروه آزمون • • متفاوت است كه نتايج اين مطالعه با مطالعات Shobeiri و

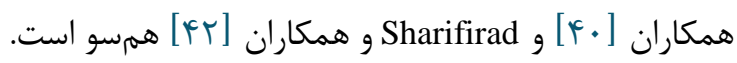

$$
\text { نتيجه كَيرى }
$$

نتايج تحليل سازههاى مدل اعتقاد بهداشتى دربارهٔ رفتار

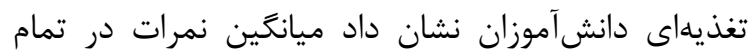

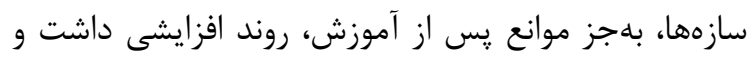

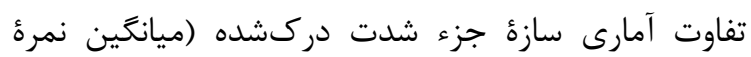

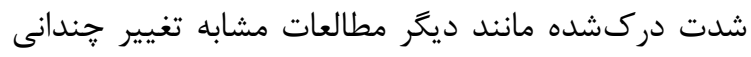
نداشت)، قبل از مداخله، بلافاصله و دو ماه بعد از آموزش ماسند معنى دار بود. از آنجا كه مادر در خانواده مهممترين راهنما

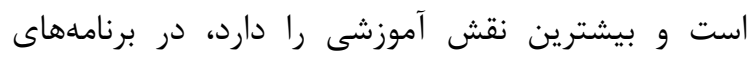
آموزشى، ييشنهاد مىشود در مراكز درمانى - بهداشتى و

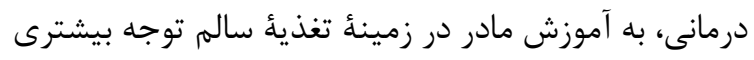

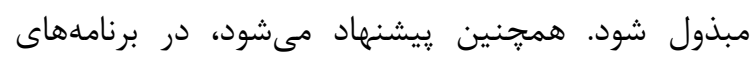

\section{References}

1. Mohammadi N, Omidi A, Amini R, Moghimbeigi A. Comparison of anthropometric indices of 13-15 year-old female students with NCHS standards in Hamadan city. journal of Pediatric Nursing. Spring. 20 16;2(3):71.

2. Karamizadeh Z, Hakimi G. The survey of physical growth and secondary sex 2characteristics of 11-14 years old girls in Shiraz. medical science. 2002;21(2):129-31.

3. Mohamadi N, Shobeiri F, Khirolahei A, Roshanaie Gh. Nutritional patterns in Iranian university students comparison between dormitoryand nondormitory states. E3 Journal of Medical Research. 2014;3(1): 001-5.

4. Mrigen Kr, Deka, Anil Kumar Malhotra, Rashmi Yadav, Gupta1 S. Dietary pattern and nutritional deficiencies among urban adolescents.. Family Med Prim Care. 2015;4(3):364-8. https://doi.org/10.4103/2249-4863.161319

5. Sheikholeslam R, Mohamad A, Mohammad K, S V. Non-Communicable disease risk factors in Iran. Asia Pac J Clinical Nutrition. 2004;2(13): 100.
6. Sechrist KR, Walker SN, Pender NJ. Development and psychometric evaluation of the exercise benefits/barriers scale. Research in nursing \& health.

1987;10(6):357-65.

https://doi.org/10.1002/nur.4770100603

7. Kotecha P, Patel SV, Baxi R, Mazumdar V, Shobha M, Mehta K, et al. Dietary pattern of schoolgoing adolescents in urban Baroda, India. Journal of health, population, and nutrition. 2013;31(4):490-6.

8. Mesías M, Seiquer I, Navarro MP. Iron nutrition in adolescence. Critical reviews in food science and nutrition. 2013;53(11):1226-37.

https://doi.org/10.1080/10408398.2011.564333 PMID:24007425

9. Norouzinia R, Aghabarari M, Kohan M, Karimi M. Health promotion behaviors and its correlation with anxiety and some students' demographic factors of Alborz University of Medical Sciences. Journal of Health Promotion Management. 2013;2(4):39-49. 
10..Motlagh Z, Mazloomy-Mahmoodabad S Momayyezi M. Study of Health-promotion behaviors among university of medical science students. Zahedan Journal of Research in Medical Sciences. 2011;13(4):29-34.

11. Rosner M. Maltese: Mixed language and multilingual technology mike rosner and Jan Joachimsen. Multilingual Processing in Eastern and Southern EU Languages: Low-Resourced Technologies and Translation. 2012 Apr 25:40.

12. Peyman N, Rastegar K, Taghipor A, Esmaili H. The effectof education on a model PEN-3 nutritional behaviors in girls 16-12 years old with obesity and overweight in Razan, Hamedan. SIDofogh danesh. 1390;5,18:254-60.

13. Bahmanpour K, Nouri R, Nadrian H, Salehi B. Determinants of oral health behavior among highschool students in Marivan County, Iran based on the Pender's Health Promotion Model. Journal of School of Public Health \& Institute of Public Health Research. 2011;9(2):93-106.

14. Karimi M, Eshrati B. The effect of health promotion model-based trainingon promoting students' physical activity. Journal of Kermanshah University of Medical Sciences (J Kermanshah Univ Med Sci). 2012;16(3):192-200[Persian].

15. Nutbeam D, Harris E, Wise W. Theory in a nutshell: a practical guide to health promotion theories: McGraw-Hill; 2010.

16. Alizadeh Siuki H, Jadgal K, Shamaeian Razavi N, Zareban I, Heshmati H, Saghi N. Effects of Health Education Based on Health Belief Model on Nutrition Behaviors of Primary School Students in Torbat e Heydariyeh City in 2012. journal of health. 2015;5(4):289-99.

17. Tomey A, Alligood M. Nursing theorists and their work sixth edition. Mosby Elsevier. St. Louis, MO; 2006.

18. Chenary R, Noroozi A, Tahmasebi R. Effective factors of health promotion behaviors based on Health Promotion Model in chemical veterans of Ilam province in 2012-13. www sjimu medilam ac ir. 2013;21(6):257-67.

19. M.Saffari D.Shojaeizadeh, F.Ghofranipour A.Heydarnia, A.Pakpour. Health Education \& Promotion Theories, Models, Methods. (Book). 2012;New Edition:53-63.
20. Sadrzadeh-Yeganeh H, Angoorany P, Keshavarz S, Rahimi A, Ahmady B. Comparison of two nutrition education techniquies on breakfast-eating practice in primary school girls, Tehran. Journal of School of Public Health and Institute of Public Health Research. 2006; 6(1): 72-6 .

21. MH B, Sh O. Survey of health and nutritional behaviors among high school students. Iranian Journal of Health Education and Health Promotion. 2014;1(4):69-80.

22. Pender NJ, Murdaugh CL, Parsons MA. Health promotion in nursing practice 2006

23. Mohebi S, Azadbakhat L, Feyzi A, Hozoori M, Kamran A, Sharifirad G. Educational Needs of Women with Metabolic Syndrome on Healthy Nutrition in Isfahan: Application of Health Promotion Model. Journal of Health. 2013;4(2):165-79

24. Pender N, Murdaugh C, Parsons M. Health promotion in nursing practice. 2006.

25. Tol A, Esmaeili Shahmirzadi S, Shojaeizadeh D, Eshraghian MR, Mohebbi B. Determination of perceived barriers and benefits of adopting healthpromoting behaviors in cardiovascular diseases prevention: Application of preventative behavior model. Journal of Payavard Salamat. 2012;6(3):204-14.

26. Sakraida TJ. Health promotion model. Nursing theorists and their work. 2010;7:434-53.

27. Khodaveisi M, Omidi A, Farokhi S, Soltanian A. Dietary Behavior Status And Its Predictors Based On The Penders Health Promotion Model Constructs Among Overweight Women referred to Fatemieh hospital clinics in Hamedan, 2014. Journal of Nursing Education. 2016;5(2).

28. Rahimi T, Dehdari T, Ariaeian N, Gohari M. Survey of breakfast consumption status and its predictors among Qom students based on the Penders health promotion model constructs. Iranian Journal of Nutrition Sciences \&amp; Food Technology. 2012;7(2):75-84[Persian].

29. Sh O. Survey of health and nutritional behaviors among high school students. Iran J Health Edu and Health Promo. 2014;1(4):69-80.

30. Safavi M, Yahyavi SH, Pourrahimi M. Impact of dietary behaviors and exercise activities education on the self- efficacy of middle school students. Med Sci J. 2012;22(2):143-51. 
4. 4 تأثير آموزش براساس مدل اعتقاد بهداشتى بر رفتارهاى تغذيهاى ....

31. Jung L-H, Choi J-H, Bang H-M, Shin J-H, Heo YR. A comparison of two differential methods for nutrition education in elementary school: lectureand experience-based learning program. Nutrition research and practice. 2015;9(1):87-91 https://doi.org/10.4162/nrp.2015.9.1.87

32. Dehdari T, Yekehfallah F, Rahimzadeh M, Aryaeian N, Rahimi T. Dairy Foods Intake among Female Iranian Students: A Nutrition Education Intervention Using a Health Promotion Model. Global Journal of Health Science. 2016;8(10):192[Persian].

33. Amini R, Moayeri E, Khodaveis M. The Effect of Health Belief Model Based Education on Breastfeedingof Unipara Mothers Referred to Imam Reza Educational Hospital. Iranian Journal of Pediatric Nursing (JPEN). 2016;3(2) [Persian].

34. Movahed E, Arefi Z, Ameri M. The Effect of Health Belief Model-Based Training (HBM) on Self-Medication among the Male High School Students. Iranian Journal of Health Education and Health Promotion. 2014;2(1):65-72.

35. King KA, Vidourek RA, English L, Merianos AL. Vigorous physical activity among college students: using the health belief model to assess involvement and social support .Archives of Exercise in Health and Disease. 2013;4(2):267-79. https://doi.org/10.5628/aehd.v4i2.153

36. Ivari TK, Heshmati H, Faryabi R, Goudarzian Z, Ghodrati A, Najafi F, et al. Effect of Health Belief Model based education on nutritional behaviors of pregnant women referred to health centers in Torbat-e-heydariyeh city. Journal of Health in the Field. 2016;3(4).

37. Lotfi Mainbolaghi B, Rakhshani F, Zareban I, Montazerifar F, Sivaki HA, Parvizi Z. The effect of peer education based on health belief model on nutrition behaviors in primary school boys. Journal of Research \& Health Social Development \& Health Promotion Research Center. 2012;2(2):214-25.
38. Taslimi Taleghani M, Jazayeri S, Keshavarz S. Sadrzadeh yeganeh H, Rahimi A. Comparison of two methods of nutrition education (pamphlets andgroup discussion) on knowledge, attitude and behavior of First grade intermediate school female students in Tehran. J School Health and Health Research Institute. 2009;2(4):69-78.

39. Shariff ZM, Bukhari SS, Othman N, Hashim N, Ismail M, Jamil Z, et al. Keywords Adolescents Children Chinese College Students Health Health Education Health Promotion Internet Knowledge Obesity Online Learning Physical Activity Smoking adolescents global health health health behavior health education health promotion physicalactivity technology. 2008.

40. Shobeiri F, Afshari KH. The effect of nutritional education based on Pender's Health Promotion Model the behavior of pregnant women referred to health centers in Hamadan. 2017:47-50[Persian].

41. Anderson AS, Campbell DM, Shepherd R .The influence of dietary advice on nutrient intake during pregnancy. British Journal of Nutrition. 1995;73(2):163-77. https://doi.org/10.1079/BJN19950021

42. Sharifirad G, Mohebi S, Matlabi M, Abasi MH, Rajati F, Tol A, editors. Effect of nutrition education Program on the recommended weight gain in during pregnancy in pregnant women; Application of Health Belief Model. The First International \& 4th National Congress on health Education \& Promotion, 2011; 2011: Tabtiz university of medical sciences. 